\title{
Absolute Prediction of the Melting and Freezing Points of Saturated Hydrocarbons Using Their Molar Masses and Atume's Series
}

\author{
Atume Emmanuel Terhemen*
}

Faculty of Natural sciences, University of Jos PMB 2084, Jos Plateau State, Alumni, Nigeria

\section{ARTICLE IN F O}

Received: 08 June 2019

Revised: 24 July 2019

Accepted: 07 August 2019

Available online: 20 August 2019

\section{K E Y W O R D S}

Melting point

Freezing point

Atume's series

Atume's formular

Saturated hydrocarbon

\section{A B S T R A C T}

This study was conducted to apply the Atume's series in the absolute prediction of melting and freezing points of a wide range of saturated liquid and solid hydrocarbons. The calculated results that were obtained, shows that a range of $92 \%$ to $99 \%$ accuracy was theoretically achieved when compared to experimental results. Basically, precise interpolations were deployed by equating the energies released by frozen liquid molecules to the energies absorbed by their corresponding boiling molecules; which represents their lower and upper energy fixed points respectively. These two fixed points were also found to vary infinitesimally and inversely to each other. The energies absorbed or released, molar masses, and trigonometric properties formed the basis for this method. In branched chain hydrocarbons, the melting points of their corresponding linear molecules were also used as reference points to determine their melting and freezing points; indicating the mathematical relationships between their fixed points and trigonometric properties.

\section{GRA PHICALABSTRACT}

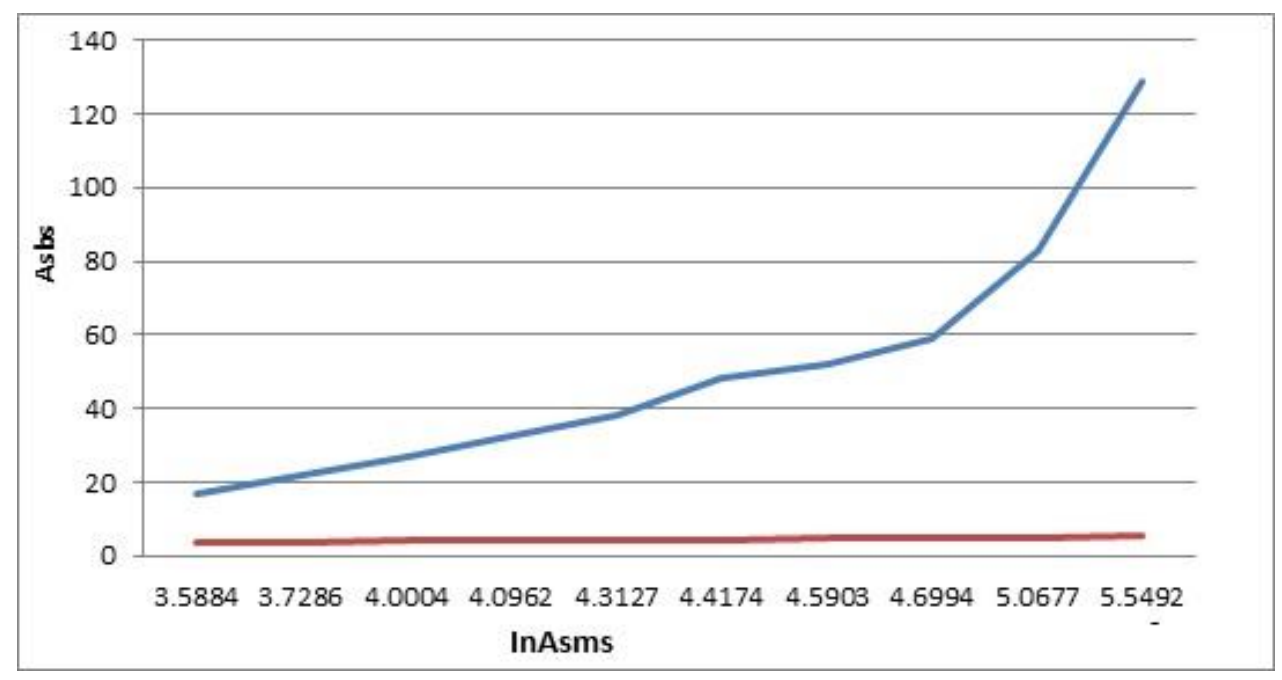

* Corresponding author's E-mail address: atumeemmanuel@gmail.com 


\section{Introduction}

The melting and freezing points of pure chemical compounds are intensive properties like density and boiling point. More so, intensive properties are independent of the amount of substance present. Experimentally, it has been discovered that, melting point is actually recorded as the range of temperatures in which the last crystal just disappears [1].

The melting point of a substance is the temperature in which it changes state from solid to liquid at atmospheric pressure. The reverse process is called the freezing point; which is known as the temperature in which the substance changes state from liquid to solid at atmospheric pressure.

The melting point of a solid is approximately the same as the freezing point of its liquid. It is also the temperature in which the rate of melting of a solid equals the rate of freezing of its liquid, under a given applied pressure. However, it can also be referred to the temperature in which its solid and liquid phases coexist in equilibrium, because the transition between the solid and the liquid is so sharp at a negligible temperature difference of approximately $0.1{ }^{\circ} \mathrm{C}$. At this particular temperature, the substance can exist as either solid or liquid [2].

Melting point is a physical property often used to identify compounds or to check the purity of the compound. Practically, it is difficult to find a melting point. In terms of melting accuracy, the best chemists can obtain falls within the range of $2-3^{\circ} \mathrm{C}$ accuracy. This result is usually sufficient in cases where melting point is used [3].

The purpose of this study is to create a new and effective method to calculate all thermodynamic state functions of a hydrocarbon, at any temperature and pressure, by using molar masses of compounds and a suitable Atume's series.

Since melting, freezing and boiling points are proportional to other thermodynamic state functions like: enthalpy, entropy, and internal energy, we can conveniently place temperatures on a scale with upper and lower energy/temperature fixed points, in order to determine any unknown thermodynamic function. All the information from this analysis will be useful in the programming of devices for chemical analysis.

\section{Important definitions and abbreviations}

Atume's formular for the melting and freezing point of $n$-alkanes is given as:

$$
\mathrm{Ms}=\frac{M^{2}}{e^{\left(\frac{A s b s}{A s r}\right)}}
$$

Atume's formular for the melting and freezing point of all saturated hydrocarbon is given as:

$$
\mathrm{Ms}=\left[\frac{M^{2}}{e^{\left(\frac{A s b S}{A s r}\right)}}\right] \operatorname{Sin} \propto
$$

Where;

Ms = the melting point of straight chain hydrocarbon (alkanes).

$\mathrm{M}_{\mathrm{b}}=$ the melting point of a branched chain hydrocarbon.

$\mathrm{M}=$ molar mass of the compound

Asms $=$ Atume's series for the melting point of straight chain alkanes also known as energy of the lower fixed point (energy loss for melting or freezing to occur).

Asbs = Atume's series for the boiling point of straight chain alkanes also known as energy of the upper fixed point (energy gained for boiling to occur).

Asr $=$ Atume's series for the ratio of Asbs to the ratio of the natural logarithm of Asms.

$$
\propto=\text { angular deviation from a }
$$
corresponding straight chain isomer as a result of conventional inductive effect of hydrocarbons in degrees [4].

$\bar{p}$ is given as inductive pressure or force per unit volume [5]. 


\section{Experimental}

\section{Method}

Estimation of absolute values for 'Asbs' from experimental results

From the molar masses of $\mathrm{C}_{5}-\mathrm{C}_{30} n$ alkanes and the experimental results of corresponding boiling points, absolute 'Asbs' values in $\mathrm{g}^{2} / \mathrm{mol}^{2} \mathrm{~K}$ were estimated by squaring the mass of one mole of each alkane molecule and the moles of their inverses. This is so because, for as many elementary entities in each alkane molecule, are also atoms in 12 grams of carbon-12, which have the value of $6.02 \times 10^{23}$ atoms per unit rise in Kelvin. The results obtained from this estimation of Asbs values for $\mathrm{C}_{5}$ $\mathrm{C}_{30} \mathrm{n}$-alkanes are shown on Table 1.

From Table 1, $B s \propto M^{2}$

(Eq.1)

\section{Assumptions}

1. 'A conventional inductive effect exists within the molecule of an $n$-alkane such that, the carbon atoms at the left and right extremes, pumps electrons into the central carbon atoms.

Table 1. Absolute estimation of 'Asbs' values

\begin{tabular}{|c|c|c|c|c|c|c|}
\hline $\mathrm{S} / \mathrm{N}$ & Compound & Formular & $\begin{array}{l}\text { Molar mass } \\
\text { (M) } \mathrm{g} / \mathrm{mol}^{-1}\end{array}$ & $\begin{array}{c}\mathrm{M}^{2} \\
\mathrm{~g} / \mathrm{mol}^{-2}\end{array}$ & $\begin{array}{c}\text { Boiling point 'Bs' } \\
\text { in Kelvin [6] }\end{array}$ & $\begin{array}{c}\text { (Asbs) } \mathrm{M}^{2} / \mathrm{Bs} \\
\left(\mathrm{g}^{2} / \mathrm{mol}^{2} \mathrm{~K}\right)\end{array}$ \\
\hline 1 & $n$-pentane & $\mathrm{C}_{5} \mathrm{H}_{12}$ & 72 & 5184 & 309.1 & 16.7713 \\
\hline 2 & $n$-hexane & $\mathrm{C}_{6} \mathrm{H}_{14}$ & 86 & 7396 & 341.7 & 21.6447 \\
\hline 3 & $n$-heptanes & $\mathrm{C}_{7} \mathrm{H}_{16}$ & 100 & 10000 & 371.4 & 26.9251 \\
\hline 4 & $n$ - octane & $\mathrm{C}_{8} \mathrm{H}_{18}$ & 114 & 12996 & 398.7 & 32.5959 \\
\hline 5 & $n$-nonane & $\mathrm{C}_{9} \mathrm{H}_{20}$ & 128 & 16384 & 423.8 & 38.6597 \\
\hline 6 & $n$ - decane & $\mathrm{C}_{10} \mathrm{H}_{22}$ & 142 & 20164 & 447.9 & 45.0190 \\
\hline 7 & $n$-undecane & $\mathrm{C}_{11} \mathrm{H}_{24}$ & 156 & 24336 & 468.9 & 51.9002 \\
\hline 8 & $n$-dodecane & $\mathrm{C}_{12} \mathrm{H}_{26}$ & 170 & 28900 & 489.3 & 59.0640 \\
\hline 9 & $\begin{array}{c}n- \\
\text { pentadecane }\end{array}$ & $\mathrm{C}_{15} \mathrm{H}_{32}$ & 212 & 44944 & 543.6 & 82.6784 \\
\hline 10 & $n$-eicosane & $\mathrm{C}_{20} \mathrm{H}_{42}$ & 282 & 79524 & 615.7 & 129.1603 \\
\hline
\end{tabular}

Figure 1. Assumed conventional inductive effects for $n$-alkanes

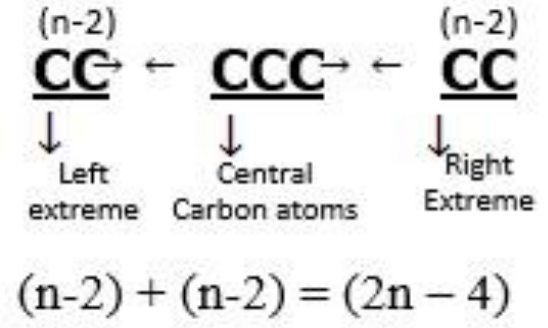

elastic repulsion of electrons from the central
2. The molecule experiences an immediate 
carbon atom(s), back to the extreme carbon atom(s) by a force known as Inductive Pressure $(\bar{p})$.

3. The pumping in and out of electrons is extremely fast (becomes slow during freezing process), resulting into kinetic energy from the molecule. Although, the energy is not high enough to cause dissociation into ions or breakage of the bonds within the molecule.

4. As the size of the molecule increase, the conventional inductive effects also increase with increasing number of carbon atoms. After the second carbon atom, the effect dies down completely so that a maximum of 2 carbon atoms pumps electrons into the central carbon chain from both extremes, making a total of 4 carbon atoms. This means the effective repulsion of electrons is proportional to $2(\mathrm{~N}-2)$ units which is equal to $\mathrm{k}(2 \mathrm{~N}-4)$ units. This implies that $\mathrm{B} \propto(2 \mathrm{~N}-4)$ units.

Nevertheless, as the length of the central carbon chain increase, the inductive pressure decreases due to the increase in the total cross sectional area or volume. Therefore, the inductive pressure is inversely proportional to $(2 \mathrm{~N}-4)$ units i.e.

$\bar{p} \propto \frac{1}{(2 N-4)}==>B s \propto \frac{1}{\bar{p}}$

For a freezing molecule; $\bar{p}$ is equivalent to Asms

$$
\begin{aligned}
& \bar{p} \propto \frac{1}{(2 N-4)}==>M s \propto \frac{1}{\bar{p}} \\
& ==>M s \propto \frac{1}{\overline{\text { Asms }}} \\
& \bar{p}=(k) \frac{1}{(2 N-4) \text { units }}
\end{aligned}
$$

If the value of $\mathrm{K}$ is unity then

$$
\bar{p}=\frac{1}{(2 N-4) \text { units }}
$$

Proof
Let us start by integrating $\bar{p}$ because the central carbon atoms do not operate as individuals but as a collective unit.

From:

$$
\begin{gathered}
\bar{p}=\frac{1}{(2 N-4) \text { units }} \\
\int \bar{p} d \bar{p}=\int \frac{1}{(2 N-4)} d \bar{p}
\end{gathered}
$$

$\bar{p}=\ln (2 N-4)$ units $=$ natural logarithm of the internal molecular energy.

Generally, an A.P which is equal to [(N-5) $0.2+3.027]^{2}$ unit was obtained by dividing each 'Asbs' value by their $\ln (2 \mathrm{~N}-4)$ values. This is a representation of the external kinetic energy for all liquid state $n$-alkanes and it is known as the Atume's series for liquid state nalkanes' [5].

Work done for boiling to take place is therefore the product of the internal molecular energy and the external kinetic energy of the n-alkanes which is equal to 'Asbs'.

Asbs $=[(\mathrm{N}-5) 0.2+3.027]^{2} \ln (2 \mathrm{~N}-4)$.

Estimation of absolute values for 'Asms' from experimental results

Using the molar masses of $\mathrm{C}_{5}-\mathrm{C}_{30} \mathrm{n}$-alkanes and the experimental results of their corresponding melting points, absolute 'Asms' values in $\mathrm{g}^{2} / \mathrm{mol}^{2} \mathrm{~K}$ were estimated by squaring the mass of one mole of each alkane molecule and the moles of their inverses, for as many elementary entities in each alkane molecule just as there are atoms in 12 grams of carbon-12 which have the value of $6.02 \times$ $10^{23}$ atoms per unit rise in Kelvin. The results obtained from this estimation of 'Asms' values from $\mathrm{C}_{5}-\mathrm{C}_{30} \mathrm{n}$-alkanes are shown on Table 2 .

Table 2 show that $\mathrm{M}^{2} \propto \mathrm{Ms}$

Using the information from Table 2, we will plot a graph of $\mathrm{M}^{2}$ against $\mathrm{Ms}$ in order to obtain a slope which corresponds to the values of 'Asms'. 
Table 2. Absolute Estimation of 'Asms' values for $n$-alkanes

\begin{tabular}{ccccccc} 
S/N & Compound & Formular & $\begin{array}{c}\text { Molar mass } \\
(\mathrm{M}) \mathrm{g} / \mathrm{mol}^{-1}\end{array}$ & $\begin{array}{c}\mathrm{M}^{2} \\
\mathrm{~g} / \mathrm{mol}^{-2}\end{array}$ & $\begin{array}{c}\text { Melting point 'Ms' } \\
\text { in Kelvin }[6]\end{array}$ & $\begin{array}{c}\text { Asms(M } 2 / \mathrm{Ms}) \\
\left(\mathrm{g}^{2} / \mathrm{mol}^{2} \mathrm{~K}\right)\end{array}$ \\
1 & $n$ - pentane & $\mathrm{C}_{5} \mathrm{H}_{12}$ & 72 & 5184 & 143.3 & 36.1759 \\
2 & $n$-hexane & $\mathrm{C}_{6} \mathrm{H}_{14}$ & 86 & 7396 & 177.7 & 41.6207 \\
3 & $n$-heptanes & $\mathrm{C}_{7} \mathrm{H}_{16}$ & 100 & 10000 & 182.4 & 54.8246 \\
4 & $n$ - octane & $\mathrm{C}_{8} \mathrm{H}_{18}$ & 114 & 12996 & 216.2 & 60.1110 \\
5 & $n$-nonane & $\mathrm{C}_{9} \mathrm{H}_{20}$ & 128 & 16384 & 219.5 & 74.6424 \\
6 & $n$ - decane & $\mathrm{C}_{10} \mathrm{H}_{22}$ & 142 & 20164 & 243.3 & 82.8771 \\
7 & $n$-undecane & $\mathrm{C}_{11} \mathrm{H}_{24}$ & 156 & 24336 & 247.0 & 98.5263 \\
8 & $n$-dodecane & $\mathrm{C}_{12} \mathrm{H}_{26}$ & 170 & 28900 & 263.0 & 109.8860 \\
9 & $n$ - & $\mathrm{C}_{15} \mathrm{H}_{32}$ & 212 & 44944 & 282.9 & 158.8127 \\
10 & $n$ pentadecane & & & & & \\
\hline
\end{tabular}

Figure 2. A graph of $\mathrm{M}^{2}$ against Ms

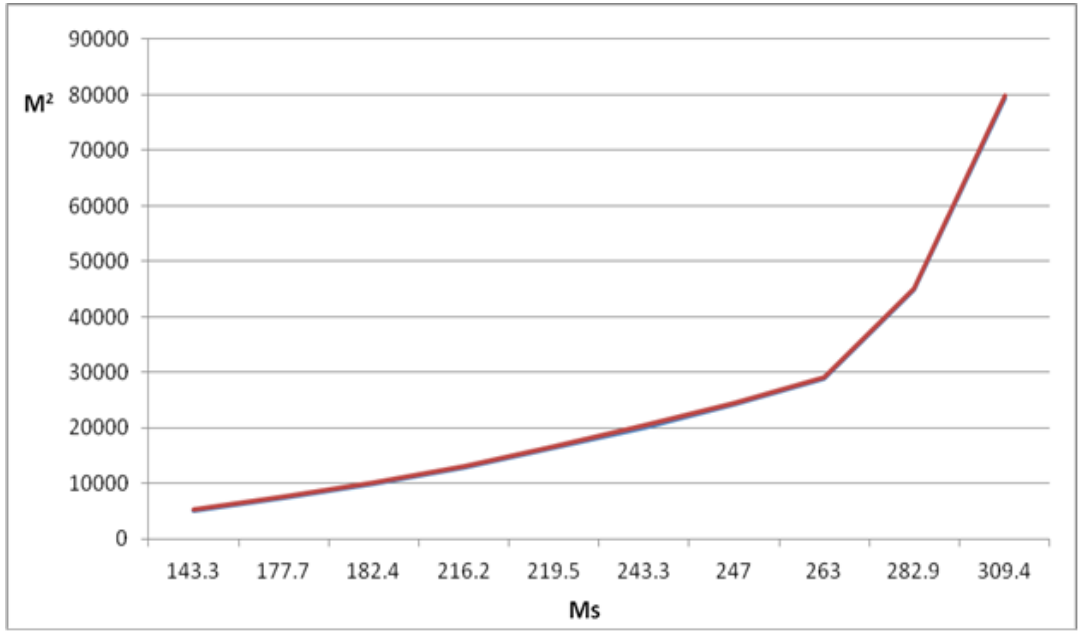

Graphically, $\mathrm{M}^{2} \propto \mathrm{Ms}$

Relationship between freezing and boiling

For freezing to occur, the molecules of a liquid have to be compressed as much as possible to form a solid. For boiling to also occur, the molecules of a liquid have to be separated as much as possible to form a gas. For a boiling liquid to be converted to a frozen solid a certain quantity of energy has to be lost; and for the frozen solid to be converted to a boiling liquid, the same quantity of energy has to be gained.

The upper and lower energy fixed points
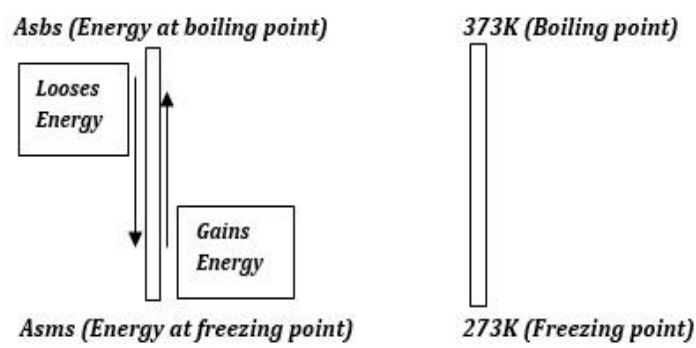
Highly compressed Asms and highly separated Asbs imply mathematically that: Asbs is proportional to the integral inverse of Asms.

Thus:

$$
\begin{aligned}
& \text { Asbs } \propto \int \frac{1}{A s m s} \\
& \text { Asbs }=\mathrm{k} \int \frac{1}{A s m s}
\end{aligned}
$$

Asbs $=\mathrm{k} \ln$ Asms

The result from Table 3 shows that Asr can be generally represented by the A.P; $\mathrm{N}[0.9+$ (N-3)0.0155] $\mathbf{~ g}^{2} / \mathbf{m o l}^{2} \mathbf{K}$ where $\mathrm{N}$ is equal to the number of carbon atoms in one molecule of the hydrocarbon. If the A.P is expanded, we will have a quadratic function which is equal to:

$$
\begin{gathered}
0.0155 \mathrm{~N}^{2}+0.85355 \mathrm{~N}=\mathbf{A s r} \\
0.0155 \mathrm{~N}^{2}+0.8535 \mathrm{~N}-\mathbf{A s r}=0
\end{gathered}
$$

For any liquid hydrocarbon, the value of Asr can be calculated by computing the appropriate value of $\mathrm{N}$ into the quadratic function. For example, the Asr value for npentane is equal to $0.0155(5)^{2}+0.85355(5)=$ 4.655 .

The quadratic function for n-pentane becomes; $0.0155 \mathrm{~N}^{2}+0.8535 \mathrm{~N}-4.655=0$. Alternatively, Asr can be obtained by plotting Asbs against ln Asms.

Table 3. Absolute estimation of 'Asr' values for $n$-alkanes

\begin{tabular}{cccccc} 
S/N & Compound & Formular & Asbs $\left(\mathrm{g}^{2} / \mathrm{mol}^{2} \mathrm{~K}\right)$ & In Asms & Asr (Asbs/In Asms) \\
1 & $n$ - pentane & $\mathrm{C}_{5} \mathrm{H}_{12}$ & 16.7713 & 3.5884 & 4.6738 \\
2 & $n$ - hexane & $\mathrm{C}_{6} \mathrm{H}_{14}$ & 21.6447 & 3.7286 & 5.8050 \\
3 & $n$ - heptanes & $\mathrm{C}_{7} \mathrm{H}_{16}$ & 26.9251 & 4.0004 & 6.7306 \\
4 & $n$ - octane & $\mathrm{C}_{8} \mathrm{H}_{18}$ & 32.5959 & 4.0962 & 7.9876 \\
5 & $n$ - nonane & $\mathrm{C}_{9} \mathrm{H}_{20}$ & 37.9435 & 4.3127 & 8.7981 \\
6 & $n$ - decane & $\mathrm{C}_{10} \mathrm{H}_{22}$ & 48.0995 & 4.4174 & 10.2095 \\
7 & $n$-undecane & $\mathrm{C}_{11} \mathrm{H}_{24}$ & 51.9002 & 4.5903 & 11.3065 \\
8 & $n$-dodecane & $\mathrm{C}_{12} \mathrm{H}_{26}$ & 59.0640 & 4.6994 & 12.5684 \\
9 & $n$-pentadecane & $\mathrm{C}_{15} \mathrm{H}_{32}$ & 82.6784 & 5.0677 & 16.3148 \\
10 & $n$-eicosane & $\mathrm{C}_{20} \mathrm{H}_{42}$ & 129.1603 & 5.5492 & 23.2839 \\
\hline
\end{tabular}

Figure 3. A graph of Asbs against ln Asms

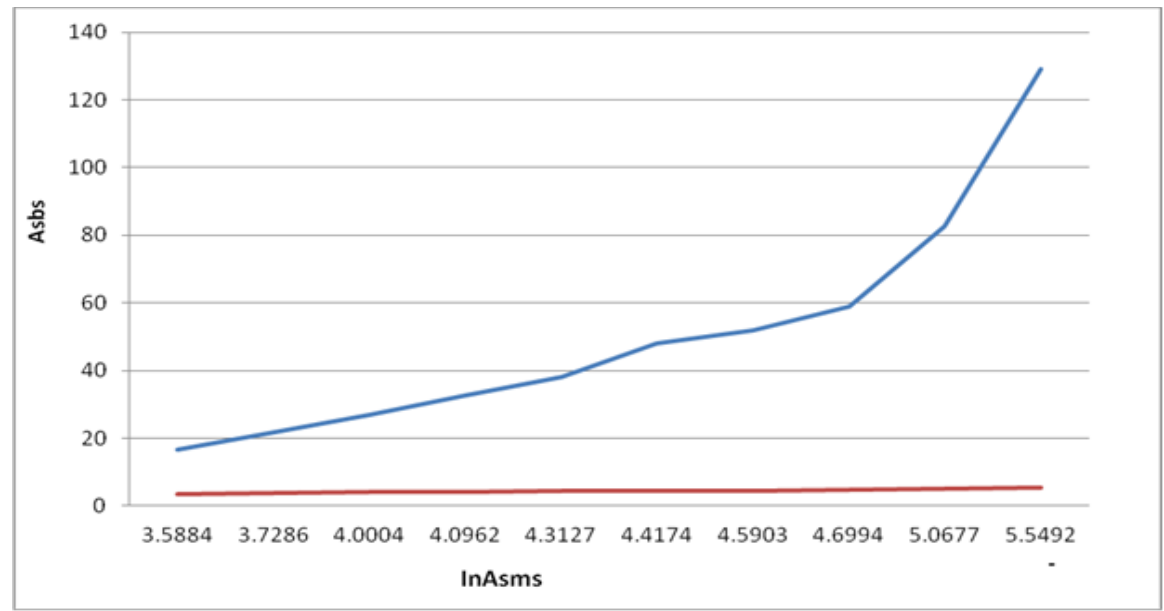


A graph of Asbs against ln Asms

The result of this plotting shows that Asbs is proportional to lnAsms with a slope that is equal to Asr.

i.e.,

Asbs $\propto \ln$ Asms

$$
\begin{gathered}
=>\text { Asbs }=(\text { Asr }) \operatorname{lnAsms} \\
\ln \text { Asms }=\frac{A s b s}{A s r}
\end{gathered}
$$

Taking the exponential of both sides of the equation

$(e) \ln$ Asms $=e^{\left(\frac{A s b s}{A s r}\right)}$

Asms $=e^{\left(\frac{A s b s}{A s r}\right)}$

\section{Recall}

$\mathrm{M}_{\mathrm{s}} \propto \mathrm{M}^{2}$

$\mathrm{M}_{\mathrm{s}} \propto \frac{1}{A s m s}$

Asms $=e^{\left(\frac{A s b s}{A s r}\right)}$

3)

Combining equations (1) and (2.1) using a unit constant

$$
\mathrm{Ms}=\frac{M^{2}}{A s m s}
$$

Substitute equation (3) into equation (4)

$$
\mathrm{Ms}=\frac{M^{2}}{e^{\left(\frac{A s b s}{A s r}\right)}}
$$

This is the formula for the melting and freezing point of liquid n-alkanes.

Atume's hypothesis states that; the freezing (melting) points of $\mathrm{n}$-alkanes is directly proportional to the square of its molar mass and inversely proportional to the energy released for freezing to occur.

For branched chain alkanes and other saturated hydrocarbons, the formula is given as:

$$
\mathrm{Ms}=\left[\frac{M^{2}}{e^{\left(\frac{A b S S}{A s r}\right)}}\right] \operatorname{Sin} \propto
$$

Where:

$$
\propto=\operatorname{Sin}^{-1} \frac{M b}{M S}[4] .
$$

Given that $\mathrm{M}_{\mathrm{b}}=$ the melting point of $\mathrm{a}$ branched chain hydrocarbon, and $\mathrm{M}_{\mathrm{s}}=$ the melting point of its corresponding straight chain isomer.

Atume's hypothesis states that; the freezing (melting) points of all saturated hydrocarbon is a sinusoidal function of that of their corresponding straight chain isomers.

Worked example

Calculate the melting points of $\mathrm{C}_{5}-\mathrm{C}_{20} n$ alkanes ( $n$-pentane down to $n$-eicosane) in Kelvin, using the Atume's formular.

\section{Solution}

\section{For n-pentane}

Molar mass of $n$-pentane $=\mathrm{C}_{\mathrm{n}} \mathrm{H}_{2 \mathrm{n}+2}=[(12 \times 5)+$ $(2 \times 5)+2]=72 \mathrm{~g} / \mathrm{mol}^{-1}$

Asbs $=[(\mathrm{N}-5) 0.2+3.027]^{2} \ln (2 \mathrm{~N}-4) \mathrm{g}^{2} / \mathrm{mol}^{2} \mathrm{~K}$

Asbs $\left.=[(5-5) 0.2+3.027]^{2} \ln (2 \times 5)-4\right)$

Asbs $=16.4174 \mathrm{~g}^{2} \mathrm{~mol}^{-2} \mathrm{k}^{-1}$

Asr $=\mathrm{N}[0.9+(\mathrm{N}-3) 0.0155] \mathrm{g}^{2} \mathrm{~mol}^{-2} \mathrm{k}^{-1}$

Asr $=5[0.9+(5-3) 0.0155]$

Asr $=4.655 \mathrm{~g}^{2} / \mathrm{mol}^{2} \mathrm{~K}$

Asms $=e^{\left(\frac{A s b s}{A s r}\right)}$

Asms $=e^{\left(\frac{16.4174}{4.655}\right)}$

Asms $=\mathrm{e}^{3.5268}=34.0160 \mathrm{~g}^{2} / \mathrm{mol}^{2} \mathrm{~K}$

$\mathrm{Ms}=\frac{M^{2}}{e^{\text {Asms }}}=\frac{72^{2}}{34.0160}=152.4 \mathrm{~K}$ 
Table 4. Compares between experimental and calculated values for ' $\mathrm{Ms}$ '

\begin{tabular}{ccccccc} 
S/N & Compound & Formular & $\begin{array}{c}\text { Melting point (K) } \\
\text { Experimental result } \\
{[6]}\end{array}$ & $\begin{array}{c}\text { Melting point } \\
\text { calculated } \\
\text { result (K) }\end{array}$ & $\begin{array}{c}\% \\
\text { Deviation }\end{array}$ & $\begin{array}{c}\% \\
\text { Accuracy }\end{array}$ \\
1 & $n$-pentane & $\mathrm{C}_{5} \mathrm{H}_{12}$ & 143.3 & 152.4 & -6 & 94.0 \\
2 & $n$ - hexane & $\mathrm{C}_{6} \mathrm{H}_{14}$ & 177,7 & 163.3 & -8.1 & 91.9 \\
3 & $n$-heptanes & $\mathrm{C}_{7} \mathrm{H}_{16}$ & 182.4 & 180.3 & -1.2 & 98.8 \\
4 & $n$ - octane & $\mathrm{C}_{8} \mathrm{H}_{18}$ & 216.2 & 198.8 & -8.0 & 92.0 \\
5 & $n$ - nonane & $\mathrm{C}_{9} \mathrm{H}_{20}$ & 219.5 & 216.8 & -1.2 & 98.8 \\
6 & $n$-decane & $\mathrm{C}_{10} \mathrm{H}_{22}$ & 243.3 & 233.5 & -4.0 & 96.0 \\
7 & $n$-undecane & $\mathrm{C}_{11} \mathrm{H}_{24}$ & 247.0 & 248.3 & +0.9 & 99.1 \\
8 & $n$-dodecane & $\mathrm{C}_{12} \mathrm{H}_{26}$ & 263.0 & 261.1 & -0.7 & 99.3 \\
9 & $n$ - & $\mathrm{C}_{15} \mathrm{H}_{32}$ & 282.9 & 286.8 & +1.4 & 98.6 \\
& pentadecane & & & & & \\
10 & $n$-eicosane & $\mathrm{C}_{20} \mathrm{H}_{42}$ & 309.4 & 295.9 & -3.0 & 97.0 \\
\hline
\end{tabular}

For n-hexane

Molar mass $=\left[\mathrm{C}_{n} \mathrm{H}_{2 \mathrm{n}+2}\right]=[(12 \times 6)+(2 \times 6)+$ $12]=86 \mathrm{~g} / \mathrm{mol}^{-1}$

Asbs $=[(\mathrm{N}-5) 0.2+3.027]^{2}+\ln (2 \mathrm{~N}-4) \mathrm{g}^{2} / \mathrm{mol}^{2} \mathrm{~K}$

Asbs $\left.=[(6-5) 0.2+3.027]^{2} \ln (2 \times 6)-4\right)$

Asbs $=21.6543 \mathrm{~g}^{2} / \mathrm{mol}^{2} \mathrm{~K}$

Asr $=\mathrm{N}[0.9+(\mathrm{N}-3) 0.0155] \mathrm{g}^{2} / \mathrm{mol}^{2} \mathrm{~K}$

Asr $=6[0.9+(6-3) 0.0155]$

Asr $=5.679 \mathrm{~g}^{2} / \mathrm{mol}^{2} \mathrm{~K}$

Asms $=e^{\left(\frac{A s b s}{A s r}\right)}$

Asms $=e^{\left(\frac{21.654}{5.679}\right)}$

Asms $=\mathrm{e}^{3.8130}=45.2916$

$\mathrm{Ms}=\frac{M^{2}}{e^{A s m s}}=\frac{72^{2}}{34.0160}=163.29 \mathrm{~K}$

\section{Conclusions}

I hereby propose that Atume's series should be used as a new intensive thermodynamic state function because, important functions like temperature, pressure, enthalpy and other thermodynamic functions can be calculated from the Atume's series, under variable conditions without necessarily searching for existing literature in the engineering tool box for thermodynamic calculations.

\section{Applications of this research article}

1. Determination of all the thermodynamic state functions of a hydrocarbon, using its molar mass, Atume's series, upper and lower energy/temperature fixed points.

2. Qualitative analysis (identification of unknown hydrocarbon).

3. Reactor design.

4. Programming devices for petroleum analysis with high level of accuracy.

\section{Acknowledgments}

I would like to express my sincere gratitude to Mr Philip Atume and Mr Charles Junior for their professional support in preparing this article. I want to also appreciate Dr. Hoda Hamidi for her patience 
and steadfast commitment during the peer review process.

\section{Disclosure statement}

No potential conflict of interest was reported by the author.

\section{References}

[1] K.W. Whitten, R.E. Davis, M.L. Peck, M.L.Peck, General chemistry. Cengage Learning, 2000, pp. 503-504

[2] Bodner research group. Division of chemistry education Purdue University, 2016,http//:www.chemed.chem.purdue. edu.

[3] R.J. Fessenden, J.S. Fessenden, Organic laboratory techniques, Brooks Cole, California, $3^{\text {rd }}$ Edition, 2000.

[4] E.T. Atume, Energy Configuration of Liquified Natural Gas/Molecular Quantization, Lambert Academic Publishing, 2017, ISBN 978-620-200579-1

[5] E.T. Atume, J. Chem. Process Eng. Res., www.iiste.org, 2012, 6, 1-6.

[6] A. Bahl, B.S. Bahl, Advanced Organic Chemistry, S. Chand and Company Ltd. Ram Nagar, New Delhi, 2009, 110 055, p 201.

How to cite this manuscript: Atume Emmanuel Terhemen, Absolute Prediction of the Melting and Freezing Points of Saturated Hydrocarbons Using Their Molar Masses and Atume's Series, Adv. J. Chem. A, 2020, 3(2), 122-130. 